This item was submitted to Loughborough's Research Repository by the author.

Items in Figshare are protected by copyright, with all rights reserved, unless otherwise indicated.

\title{
An exploration of key information models and their relationships in global manufacturing decision support
}

PLEASE CITE THE PUBLISHED VERSION

PUBLISHER

Professional Engineering Publishing / @ IMECHE

VERSION

VoR (Version of Record)

LICENCE

CC BY-NC-ND 4.0

\section{REPOSITORY RECORD}

Liu, Shaofeng, and R.I.M. Young. 2019. "An Exploration of Key Information Models and Their Relationships in Global Manufacturing Decision Support”. figshare. https://hdl.handle.net/2134/4763. 
This item was submitted to Loughborough's Institutional Repository (https://dspace.lboro.ac.uk/) by the author and is made available under the following Creative Commons Licence conditions.

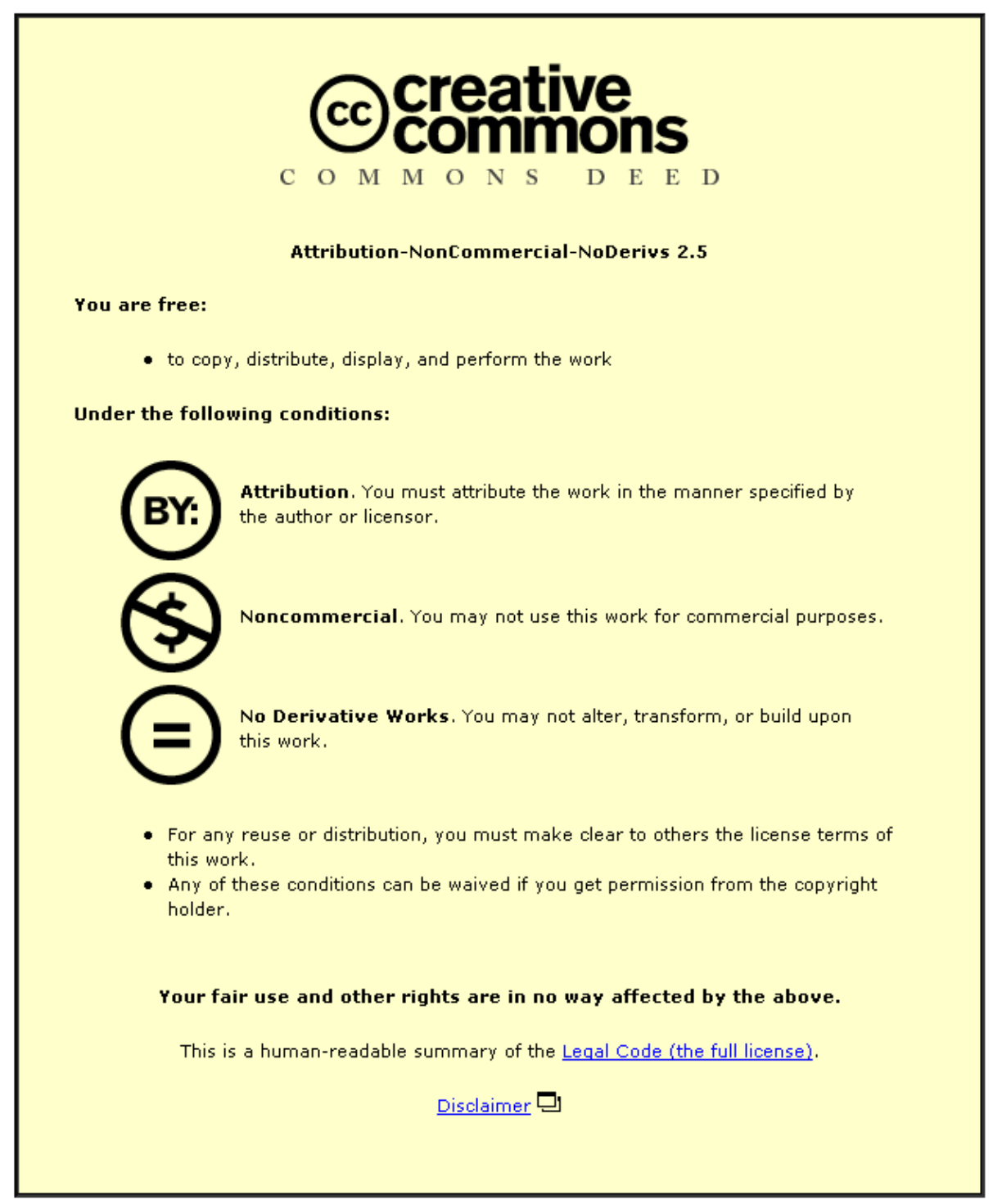

For the full text of this licence, please go to: http://creativecommons.org/licenses/by-nc-nd/2.5/ 


\title{
An exploration of key information models and their relationships in global manufacturing decision support
}

\author{
Shaofeng Liu' ${ }^{1}$ and R I M Young ${ }^{2^{*}}$ \\ ${ }^{1}$ Computer Aided Design Centre, University of Strathclyde, Glasgow, UK \\ ${ }^{2}$ Wolfson School of Mechanical and Manufacturing Engineering, Loughborough University, Loughborough, UK
}

The manuscript was received on 19 December 2005 and was accepted after revision for publication on 30 November 2006.

DOI: 10.1243/09544054JEM531

\begin{abstract}
Global manufacturing businesses are beginning to benefit from the information and knowledge support provided by modern IT tools such as Product Lifecycle Management (PLM), Enterprise Resource Planning (ERP), and Customer Relations Management (CRM). Many types of information and knowledge, from customer requirements through product information to global enterprise manufacturing capability are involved in global manufacturing decisions. Understanding the appropriate structures and relationships for this information and knowledge is a significant issue if effective wide-ranging support is to be provided.

This paper focuses on global manufacturing decision support and explores three key types of information and knowledge relationship: (a) relationships between information and knowledge elements within a single information and knowledge model; (b) relationships between different information and knowledge models at one organizational level; (c) relationships between different information and knowledge models at different organizational levels. The corresponding information and knowledge structures have been presented with Unified Modelling Language (UML) to show the multiplicity of relationship required, and these are explored with an experimental system based on Rational Unified Process, Visual $\mathrm{C}++$, and object-oriented DBMS ObjectStore. A case study has been pursued to explore the application of the information and knowledge models to a real industry environment.
\end{abstract}

Keywords: information and knowledge modelling, Product Lifecycle Management, multiple relationships, global manufacturing, decision support

\section{INTRODUCTION}

The contribution of information and communication technology to the success of global manufacturing business has been frequently stressed [1-3]. The success of the Internet and World Wide Web as a communication medium and source of information has led to the vision that providing the right information to the right person at the right time and in the right format anywhere within a global enterprise can be realized. Further, the emergence of ERP, PLM, and CRM as informationcentred tools has increased the importance of

*Corresponding author: Wolfson School of Mechanical and Manufacturing Engineering, Loughborough University, Loughborough LE11 3TU, UK. email: R.I.Young@lboro.ac.uk understanding business information structures and relationships. Progress is being made through the combination of distributed object standards (e.g. CORBA) with the Web standards and protocols for enterprise's information systems (e.g. CAD, PLM, ERP) [4].

A key issue is the provision of information and knowledge frameworks to support information sharing [5], because information sharing between participating members is a critical determinant of collaboration [6]. Global corporation practice also suggests that sharing of information results in higher levels of global product development team members' collaboration and higher achievement of global product development team goals [7].

The success of information sharing depends on many factors such as trust and the economic value 
of information. However, once the participating members in a global enterprise are willing to share information, it is technically crucial to design common information and knowledge structures to be able to capture and retrieve the right information and knowledge and make it available for making good decisions $[\mathbf{8}, \mathbf{9}]$. In object-oriented systems, information and knowledge are represented by many information and knowledge classes and objects. System behaviour is achieved through the collaboration of the objects in the system, which is often referred to as one object sending a message to another object. It is these information and knowledge relationships that provide the conduit for object interaction and collaboration. However, understanding and defining the necessary information and knowledge relationships remains a key task for effective information and knowledge support systems.

The definition of the information and knowledge bases, required for global manufacturing decision making, is complex in terms of the many types of information and knowledge that are involved. Information and knowledge modelling is necessary to build an understanding of the complex information and knowledge relationships that provide the conduit for the effective interactions between different information and knowledge objects. This paper uses visual modelling technology with UML and discusses the multiplicity of the relationships between information and knowledge in three particular information and knowledge models for global manufacturing: product models, order models, and manufacturing models.

\section{INFORMATION AND KNOWLEDGE MODELS FOR GLOBAL MANUFACTURING}

A global manufacturing business is typically based on international outsourcing strategies, i.e. to make the best use of factor-inputs (such as raw materials, products, or labour) to maximize global market opportunities. An enterprise is organized by functions and in levels, their decisions are made within multiple functions and multiple levels. Integrated decision-making in relationship to global manufacturing business means that the different categories of decision made within various functions and levels should be consistent in the sense that they contribute to the achievement of global objectives of the global enterprise. Two types of decision can be distinguished within the decision-making process related to global manufacturing, as illustrated in Fig. 1: decisions concerning 'configuration' and decisions concerning 'coordination' $[\mathbf{1 0}]$. The functions (plan, source, make, deliver, and return) shown in Fig. 1 are referenced to SCOR model definition
[11]. The two levels (local level and global level) of the organization are defined by [12].

The information and knowledge requirements for global manufacturing decision making have been explored through a multiple-perspective modelling approach comprising IDEF0 activity modelling, IDEF3 process modelling, and UML [13-15]. This has led to a classification of the information and knowledge to support global manufacturing coordination decisions into three major types: manufacturing capability related information and knowledge, product-related information, and orderrelated information [16]. The respective information and knowledge models are termed a manufacturing model (MM), a product model (PM), and an order model $(\mathrm{OM})$, as illustrated in Fig. 2. The concept of the MM and the PM has been widely accepted [17-19]. This paper takes the concept of these three information models in the global manufacturing domain, and focuses on the information and knowledge relationships required between these information models.

In terms of global manufacturing decision support, the manufacturing model's requirement can be defined at two levels, a manufacturing model at a global level (G_MM) and a manufacturing model at local level (L_MM), as shown in Fig. 3. The L_MM holds the local manufacturing capability information consisting of factory resource information (machine tools, cutting tools, and fixtures, etc.), factory process information (such as drilling and milling), and manufacturing strategies (constraints on the use of resources and processes). The G_MM, on the other hand, holds the global manufacturing capability information and knowledge including enterprise configuration, transportation between the facilities, coordination among local activities, etc.

The structures of the G_MM and L_MM have both been explored. References [20] and [18] define three main classes of information for the L_MM: factory process information, factory resource information, and a strategy class, which describes the compatibility between product features and manufacturing processes. Reference [16] defines the structure of the G_MM with four main classes: global process information, global resource information, configuration information, and a knowledge class, as shown in Fig. 4. Meanwhile, at the global enterprise level, the information of the product structure and views of the product have been modelled in the PM, while customer order information is captured in the OM.

As shown in Fig. 4, three critical relationship types have been identified between the information and knowledge models.

1. The relationship between information elements within one model. This includes the relationship 


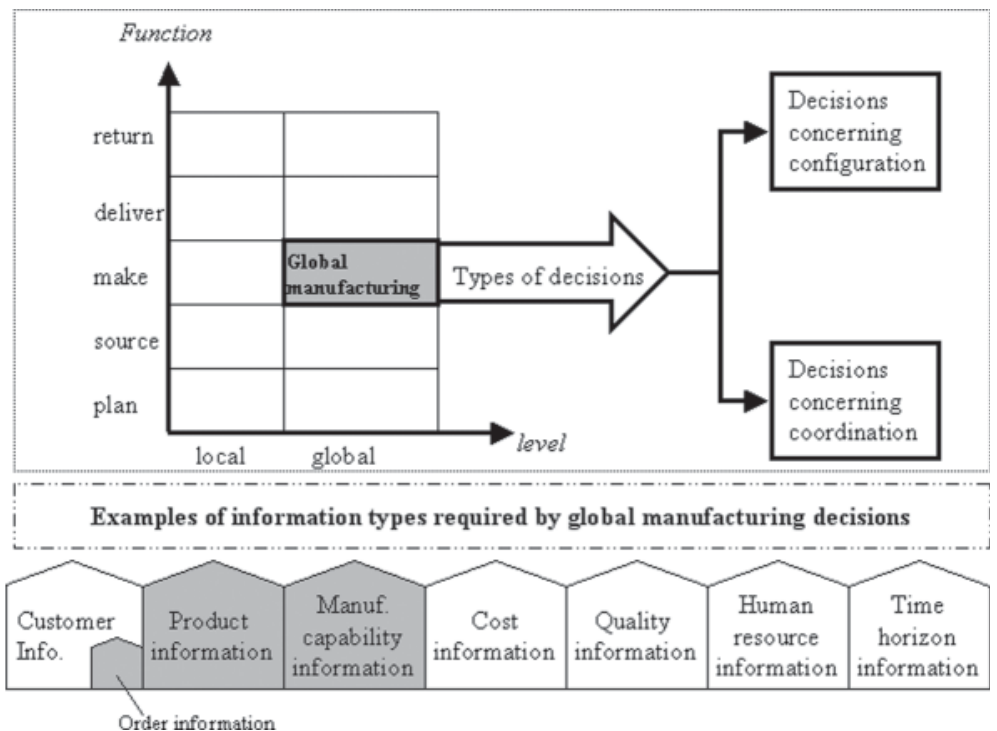

Fig. 1 Types of decision in global manufacturing and required information examples

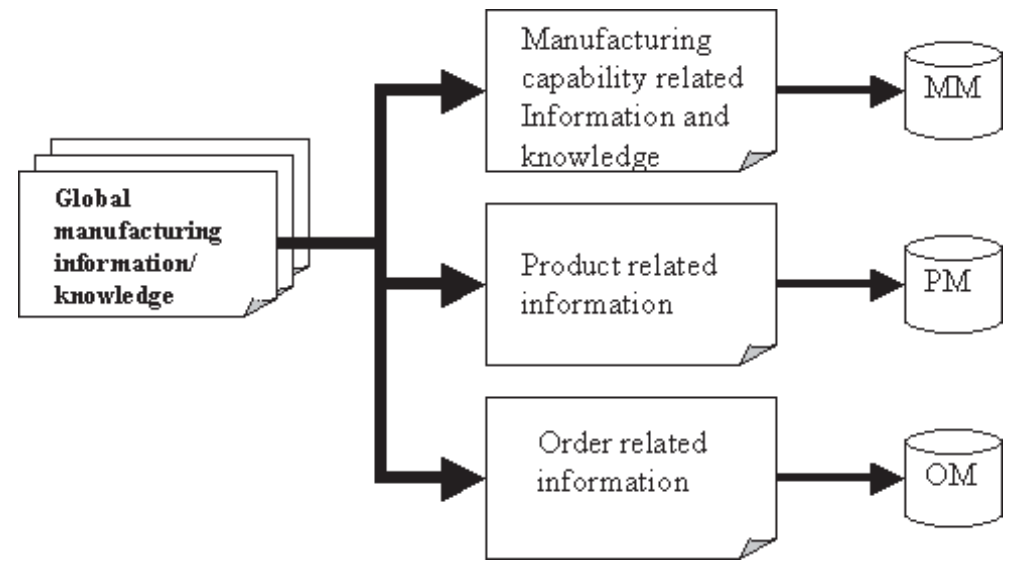

Fig. 2 Information and knowledge requirements for global manufacturing

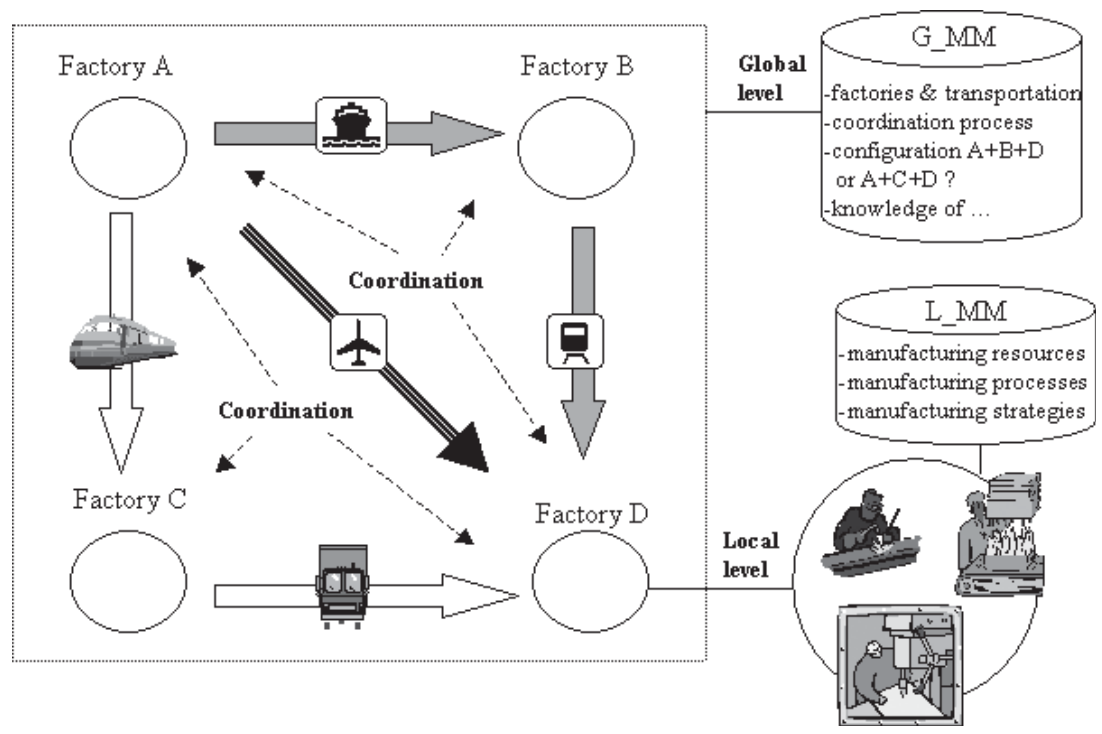

Fig. 3 An example to show global and local manufacturing capability information 


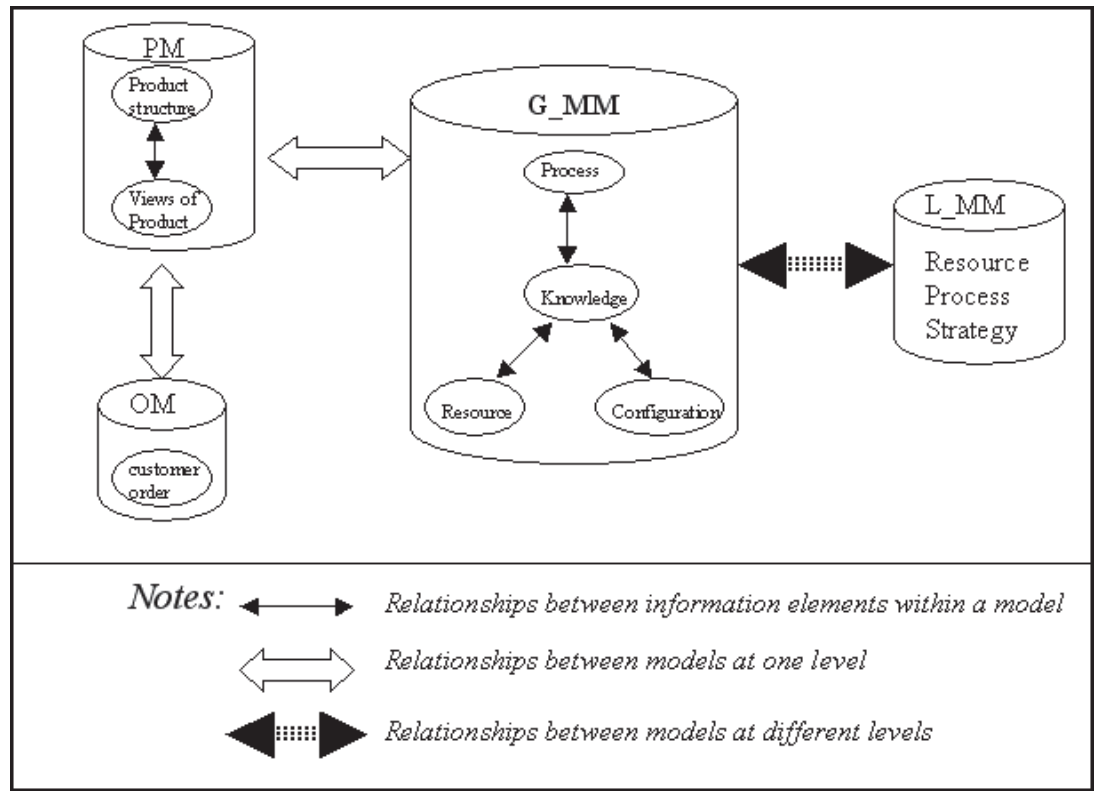

Fig. 4 An overview of the multiplicity relationships of information and knowledge

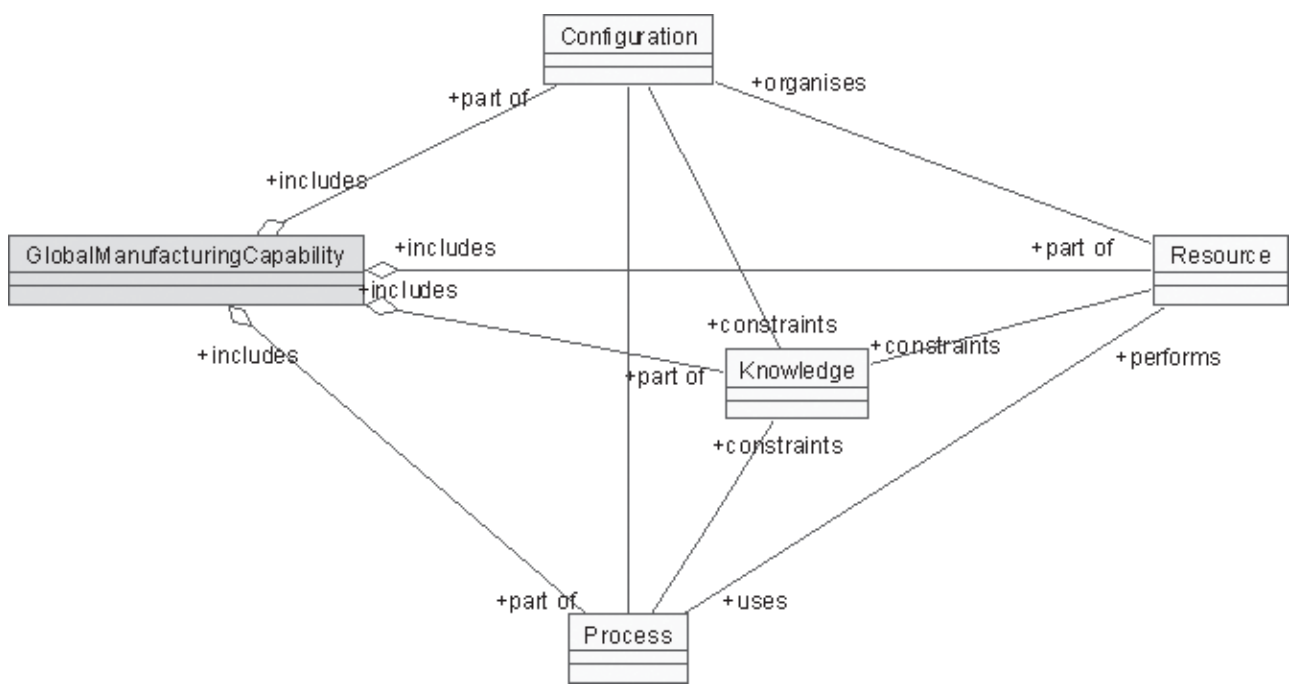

Fig. 5 Knowledge elements in the G_MM

between the process, resource, configuration, and knowledge within the G_MM, and the relationship between product structure and views of product within the PM.

2. The relationship between different models at one organizational level, i.e. global enterprise level, including the links from the G_MM to PM and OM.

3. The relationship between models at different organizational levels. This contains the interaction between the G_MM and L_MM.

The following three sections will discuss the three categories of information and knowledge relationships respectively before the experimental implementation and case study is presented in section 6 . Some conclusions are drawn in section 7 .

\section{RELATIONSHIPS BETWEEN INFORMATION ELEMENTS WITHIN THE MODELS}

\subsection{Knowledge to capture information relationships in G_MM}

The top-level structure of the global enterprise manufacturing model, i.e. G_MM, has been discussed in [16] and represented as in Fig. 5. Global manufacturing capability includes Process, Resource, Configuration, and Knowledge. Association relationships have been specified between the four main classes to indicate that there is a bidirectional communication between any two associated classes. For example, Process uses Resource and Resource performs 


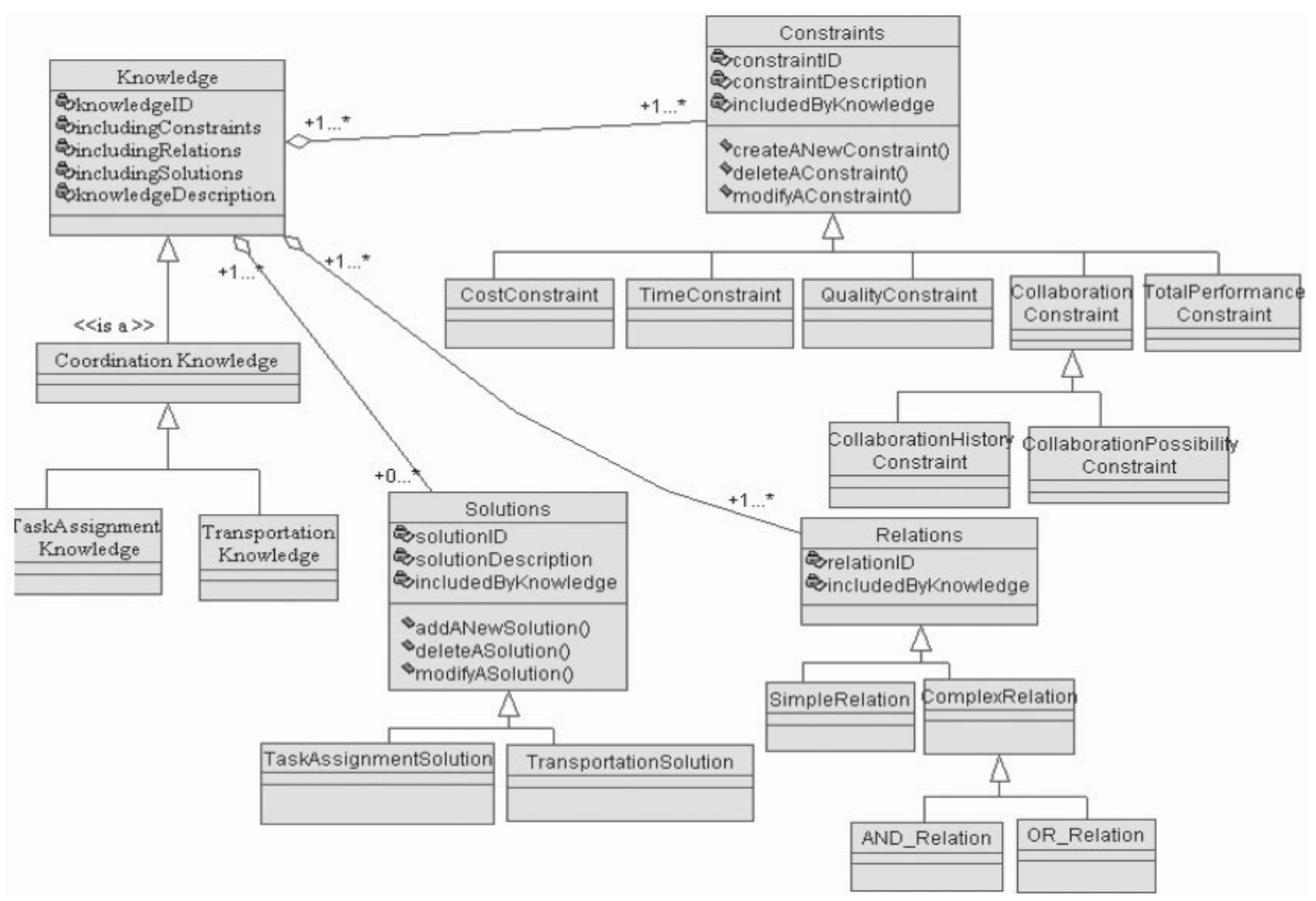

Fig. 6 Knowledge structure in the G_MM

Process, Configuration arranges Resource, and Resource affects Configuration. To implement successfully a global manufacturing strategy, proper rules have to be set on process, resource, and configuration to capture the relationships between them. This has been realized by the definition of the Knowledge class.

Generally, knowledge defines the relationships between information [21], which is in line with [22] and [23]. In other words, knowledge consists of relations between facts and decisions $[\mathbf{2 4}, \mathbf{2 5}]$. With respect to the global manufacturing capability modelled in the manufacturing model (G_MM), knowledge can be seen as a structured set of information, providing the solutions for the global manufacturing decisions based on specific constraints to process, resource, and configuration. Specific kinds of knowledge can be modelled as required under the superclass of Knowledge. Figure 6 shows the Knowledge structure in the manufacturing model (G_MM) and highlights its three elements: Constraints, Relations, and Solutions. Therefore, the Knowledge class is used to identify appropriate Solutions according to the specific Constraints and Relations. For example, to support the TaskAssignmentSolution, five subclasses have been created under the Constraints class: CostConstraint class, TimeConstraint class, QualityConstraint class, CollaborationConstraint class, and TotalPerformanceConstraint class.
Further classification of CollaborationConstraint has been modelled by the creation of its subclasses.

Relations in the knowledge structure can exist in two ways. They can exist between constraints and solutions, so as to express the idea that constraints directly influence the solutions of the problems. Relations can also exist between two constraints so as to express the idea that a constraint works together with other constraints to lead to a solution, such as AND_Relation and OR-Relation to perform complex relations [26].

Therefore, by definition of the Knowledge class to capture the Constraints to specific domain information and the Relations between the Constraints, different elements of information in the G_MM can communicate and collaborate with each other, which provides the intelligence to retrieve problem solutions for global manufacturing under different conditions and the combinations of the conditions.

\subsection{The modelling information relationship between product structure and manufacturing view within the PM}

The product definition data model provides the generic representation of how a product can be defined by a set of definitions and be grouped by 


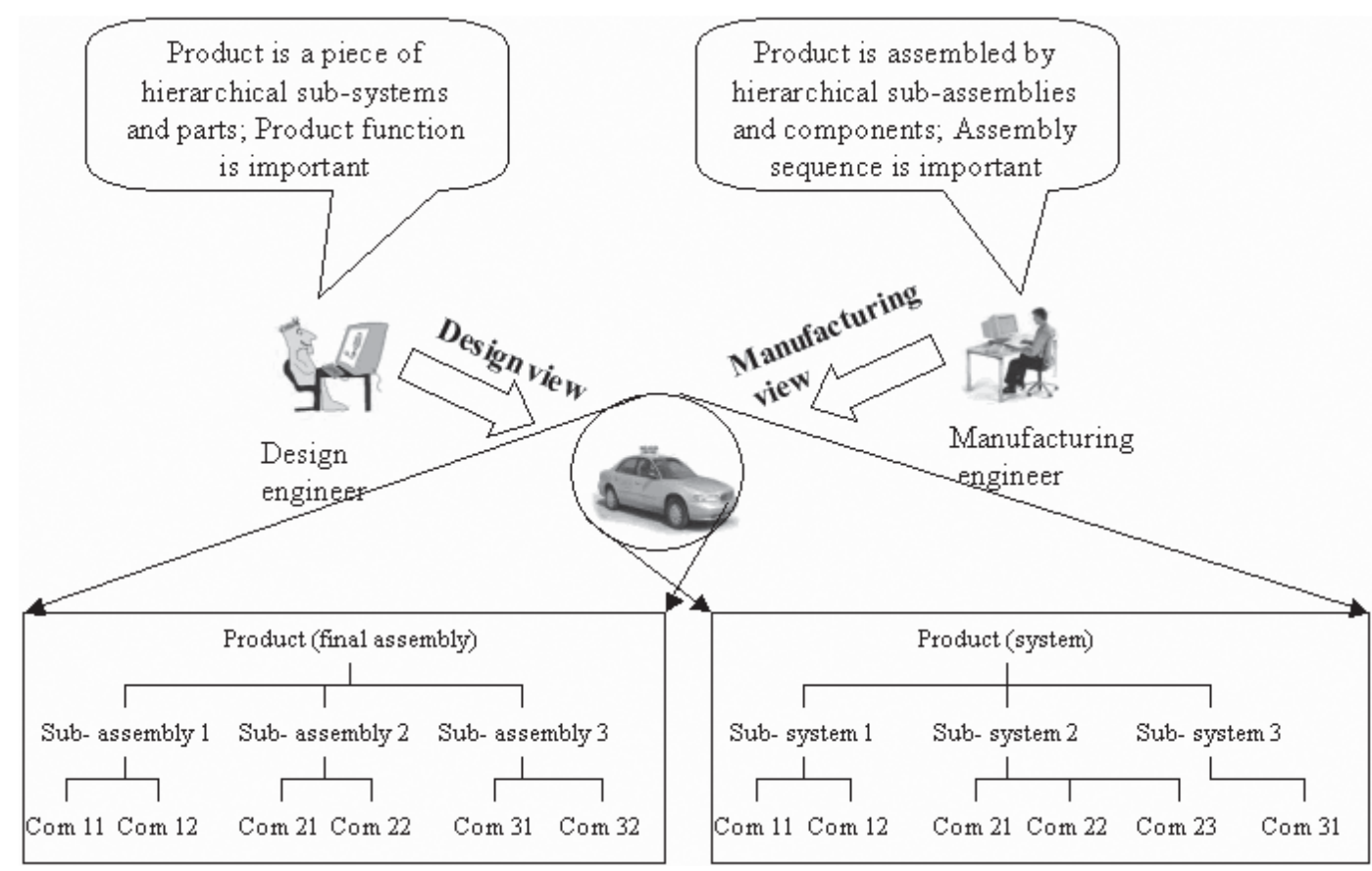

Fig. 7 Different views of a product structure

a set of versions [27]. The goal of the product information structure is the management of all relevant information of a product type [28]. In this context, the perception of relevant information can be outlined as anything that is a consideration or a result of a manufacturing decision. Such a decision can bear reference to any stage of a product's life cycle. Moreover, such a decision can be concerned with elements of different aspects of a product, which can address geometry, material, tolerance, surface finish, and product volume [29]. However, with respect to global manufacturing, decisions are especially related to specific aspects of the product information; namely, product structure and manufacturing view as described below.

Product structure defines a product in terms of its composition as a set of constituents or consumed products (ISO 10303-44). Taking its constituents' point of view, it means that a product can be seen as a system. The system can be generally considered as a conglomeration of objects that perform a specific function [30]. A system can be decomposed into different subsystems, further into smaller subsystems and finally into components. A component is a product that is not subject to decomposition from the perspective of a specific application (ISO 10303-1). As an example of a mechatronic product, consider a car and its engine assembly. The car is an automotive system, its function is to transport on land from one place to another place. The engine assembly is part of the power system, one of the many systems in a car. The power system provides power to propel a car, which also includes a fuel system, a cooling system, a lubrication system, and an exhaust system. Thus, the car has been decomposed into three system levels, while the function of objects is still referred to. Taking another point of view, i.e. from a manufacturing point of view, a product can be seen as a final assembly that has a series of hierarchical subassemblies, further with components (Fig. 7). This interpretation is quite different from the understanding of the product structure, which takes a design view of the product. To address these two different views, two kinds of bill of materials (BOM) have been referenced, commonly described as engineering bill of material (E_BOM) and manufacturing bill of material (M_BOM) [31].

E_BOM is used by a design engineer to represent the designed product structure. Its structure is viewed as a series of hierarchical subsystems that functionally form the product. M_BOM is used by manufacturing engineers for process planning. Its structure is viewed as a series of hierarchical subassemblies, displaying how a product is assembled on the shop floor. However, there is a close link between these two views. An E_BOM can be transformed into the M_BOM by considering the required assembly sequences and constraints.

Based on the understanding of the above description of product structure and views of a product, the information relationship has been modelled as shown in Fig. 8. The specification of the aggregation relationship between Product class and View class indicates that a product with a particular structure can link to one or many views, among which the 


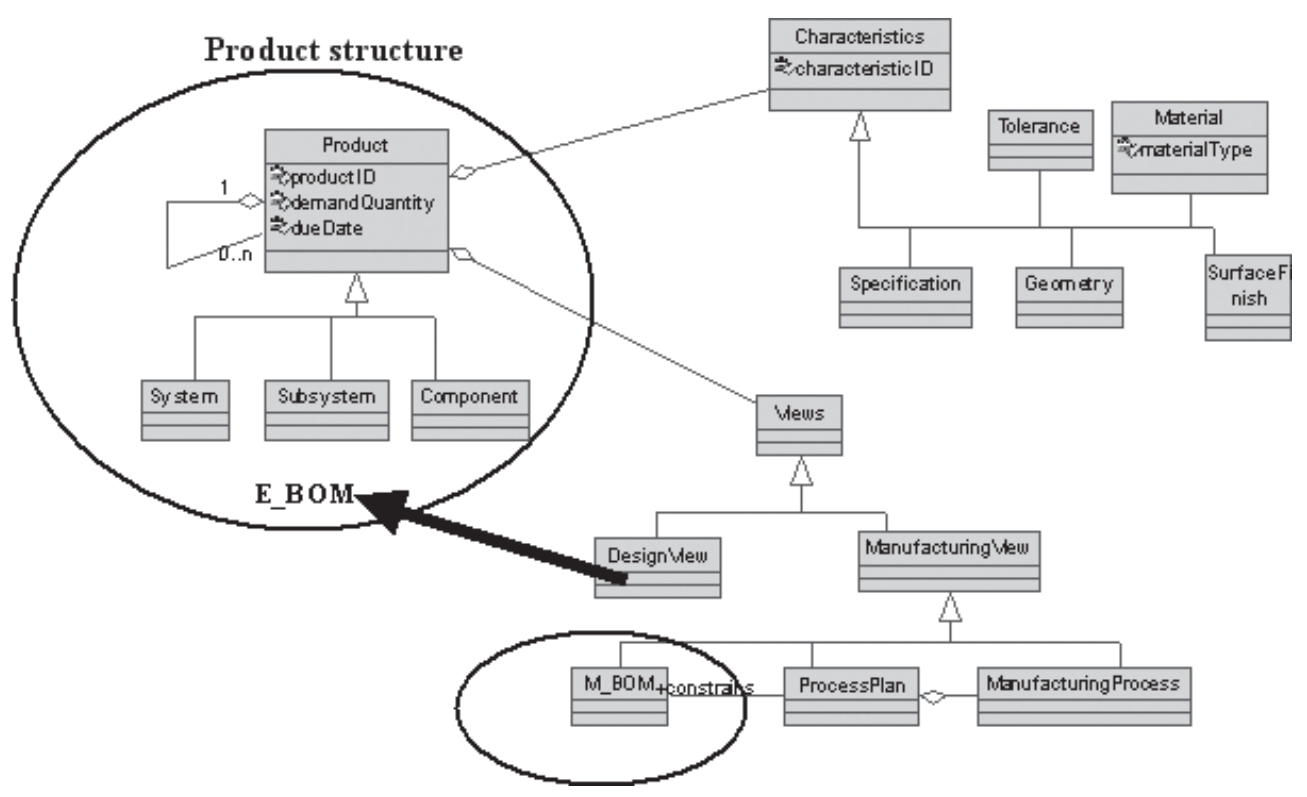

Fig. 8 Manufacturing views related to product structure in the PM

manufacturing view captures the M_BOM information. The product information structure is modelled from the design point of view, which reflects the E_BOM information.

\section{MODELLING INFORMATION RELATIONSHIPS BETWEEN DIFFERENT MODELS}

The investigation of the relationships between the three information and knowledge models is crucial to ensure that the MM, OM, and PM can work together to support global manufacturing decisions effectively. Among the three models, the product model plays the role of an intermediate bridge to connect with the order model and the manufacturing model (i.e. G_MM).

\subsection{Link from the product model to the manufacturing model (G_MM)}

The link from the PM and the G_MM is shown in Fig. 9. Its complex relationship has been established on the ManufacturingProcess class under the ManufacturingView in the PM and the ManufacturingProcess class under the Process class in the G_MM. The information structures of the two ManufacturingProcess classes are the same; however, the instances of objects are different. The G_MM holds all manufacturing processes for all products and the PM only has specific instances of the manufacturing processes for a particular product realization. This mechanism allows a one-way interaction from the PM to the G_MM. This means that the communication between the product properties and global manufacturing capabilities can only be initialized by product information, i.e. according to the product characteristics information, appropriate manufacturing process information, resource information, configuration information, and knowledge can be retrieved, while the G_MM cannot start the communication with the PM. This adapts the situations that manufacturing enterprises are driven by global markets (customer orders and products), but market requirements are not decided by manufacturing capabilities of global enterprises.

\subsection{Link between the PM and the OM}

The link between the order information and the product information is realized by recognizing the unique identification of products and the 'part of' relationship between a product and an order, which has been facilitated to implement in the objectoriented environment taken in this work. As shown in Fig. 10, through the productIDs, the bi-directional relationship can be realized, which means that if order information is known its product information can always be obtained. On the other hand, according to the product information, it is possible to identify the order that holds the product.

\section{RELATIONSHIPS BETWEEN MANUFACTURING MODELS AT GLOBAL LEVEL AND LOCAL LEVEL}

The G_MM needs the support from the L_MM to perform the function properly, because local manufacturing capability information forms the fundamental inputs to global manufacturing capability, such as potential manufacturing facility information. 


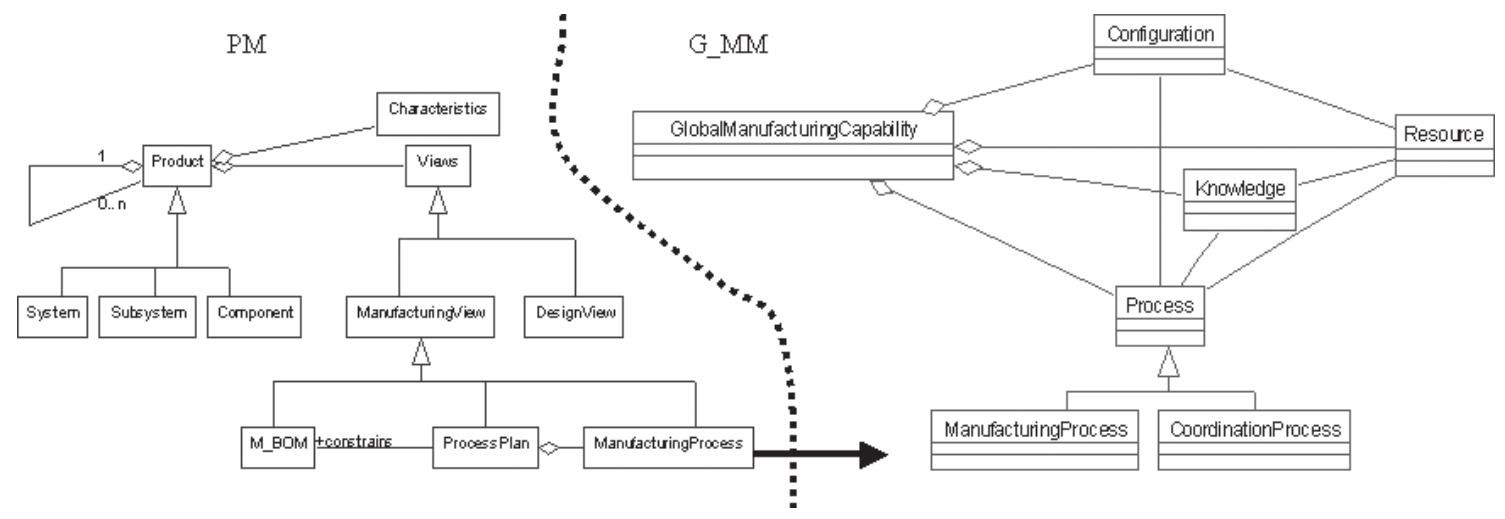

Fig. 9 Relationship between product and global manufacturing capability information

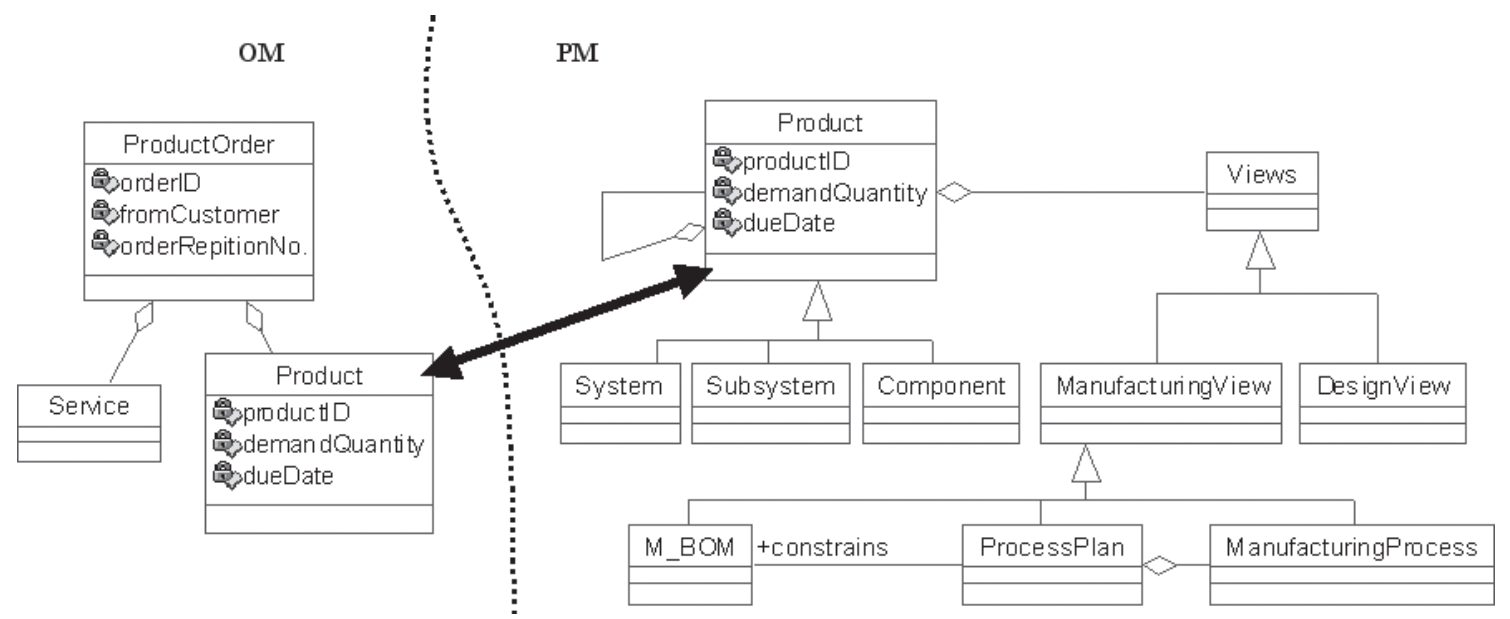

Fig. 10 Relationship between order and product information

In order to understand the relationship between the manufacturing model at a global level and a local level, i.e. between G_MM and L_MM, two levels of process planning have been referenced; macroprocess planning and microprocess planning [28]. First, the macroprocess planning is based on physical product features and only focused on assigning candidates of manufacturing processes to designed parts of a product. It is time and company independent. Second, the microprocess planning should be able to perform its traditional task of generating detailed process plans in the preparation of the actual production. In terms of global manufacturing, at global enterprise level, the focus is on macroprocess planning, i.e. to identify the specific types of manufacturing process, for the designed product under development while leaving the microprocess planning to local level. However, in the global enterprise level process planning, the relationship between the manufacturing processes is important for the implementation of the coordination process, because it is necessary to know what processes can be performed concurrently and what processes must be performed serially [32].
Once the link between the product model and the manufacturing model has been built through the manufacturing process, the required manufacturing resources can be accessed by the process evaluation of a manufacturing facility at the local level [33]. For example, the manufacturing model at a local level describes the compatibility of manufacturing processes with materials, specific product features, production quantities, and other important product attributes provided by a product model. This interaction between the product model and the manufacturing model across both global enterprise level and local level is illustrated in Fig. 11. At local level, according to the product features captured in the product model, the qualification of a manufacturing facility for specific processes can be recognized by process evaluation. If a facility has been identified for the specific processes, then it is transferred into an enterprise level manufacturing model as a potential facility. At the enterprise level, according to the E_BOM information provided by the product model, an M_BOM can be generated. As a manufacturing point of view, macroprocess planning based on the M_BOM needs to search for required manufacturing 


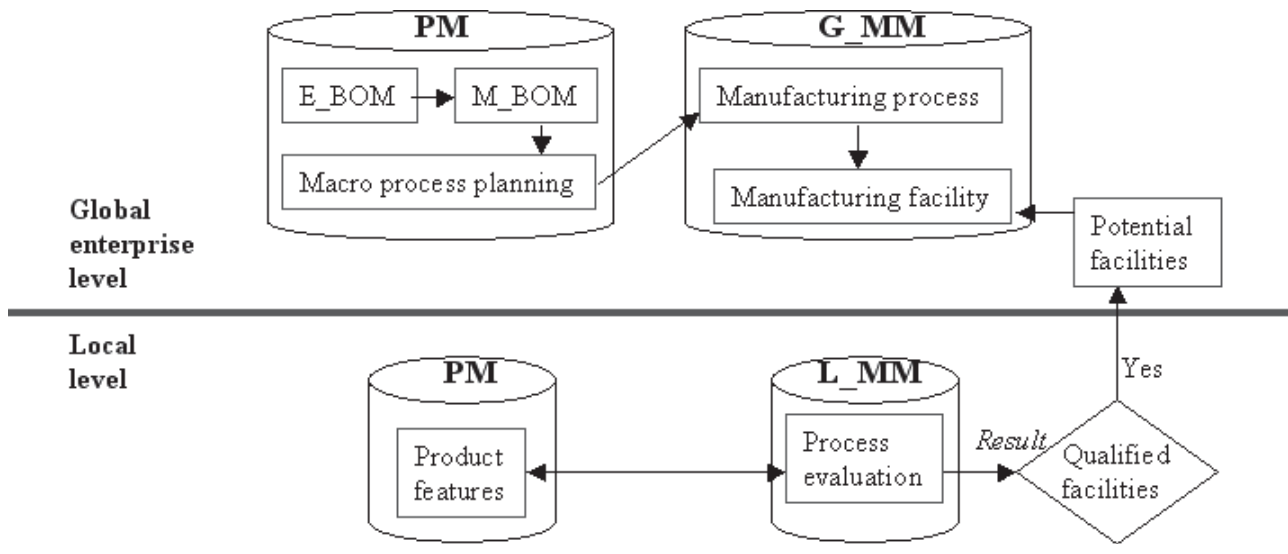

Fig. 11 Relationship between global enterprise and local manufacturing capability information

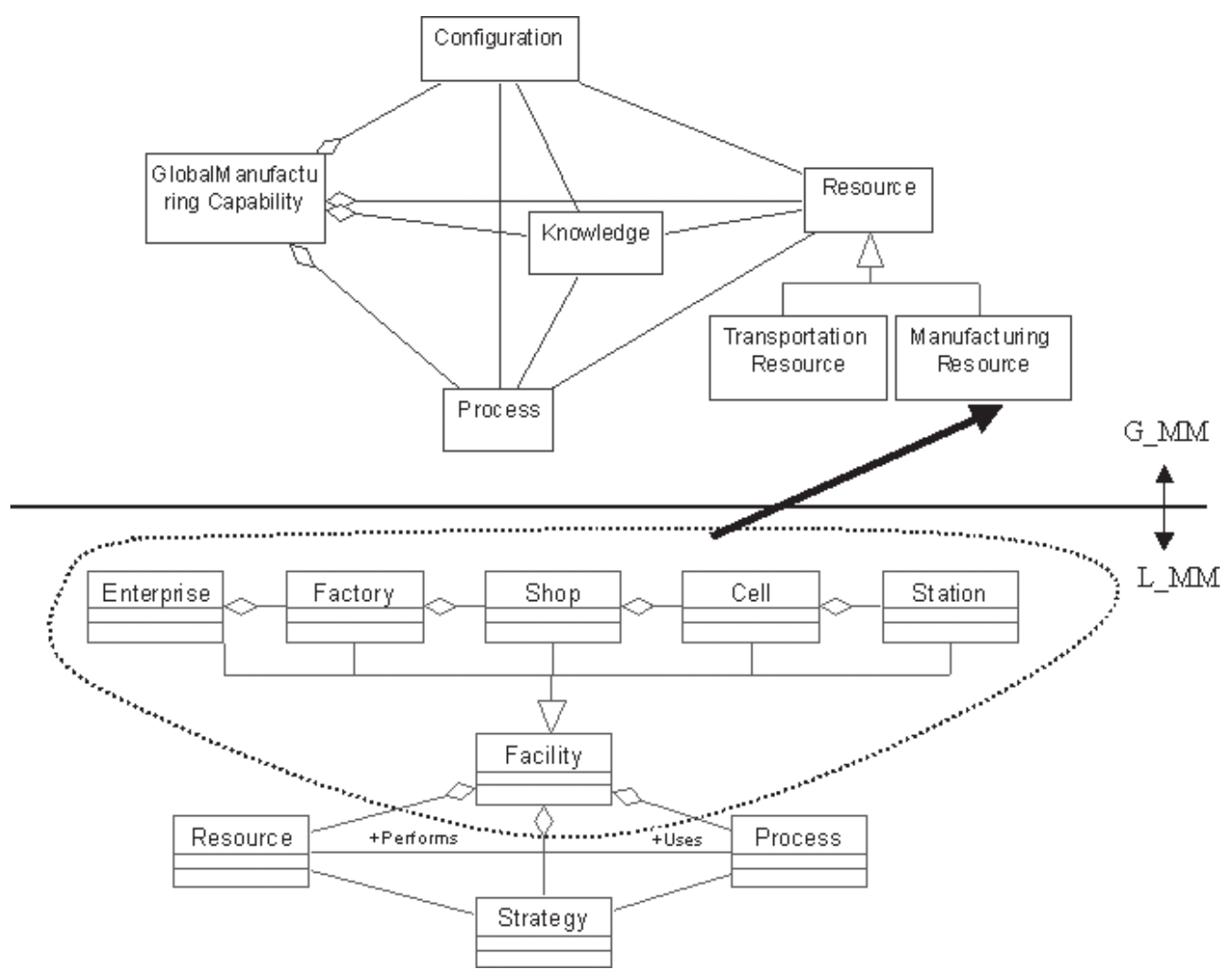

Fig. 12 Information relationship between G_MM and L_MM modelled with UML

processes in the manufacturing model and the potential facilities qualified for the manufacturing processes. Therefore, the global level manufacturing model receives the required support from the local level manufacturing model.

To model the above information relationship between G_MM and L_MM, the bridge is built on the creation of the subclasses of Resource class in the G_MM. As seen from Fig. 12, one of the global resources is a manufacturing resource, i.e. manufacturing facilities. The information structure of the L_MM captures the local manufacturing process, resource, and strategy belonging to a local manufacturing facility $[\mathbf{1 8}, \mathbf{2 0}]$, which form the inputs of potential manufacturing facilities for the G_MM.

The investigation of the relationship between the G_MM and L_MM is the key to successful integration of global decisions and local decisions.

\section{APPLICATION OF THE INFORMATION AND KNOWLEDGE RELATIONSHIPS}

In order to explore the applications of the information and knowledge relationships between the 


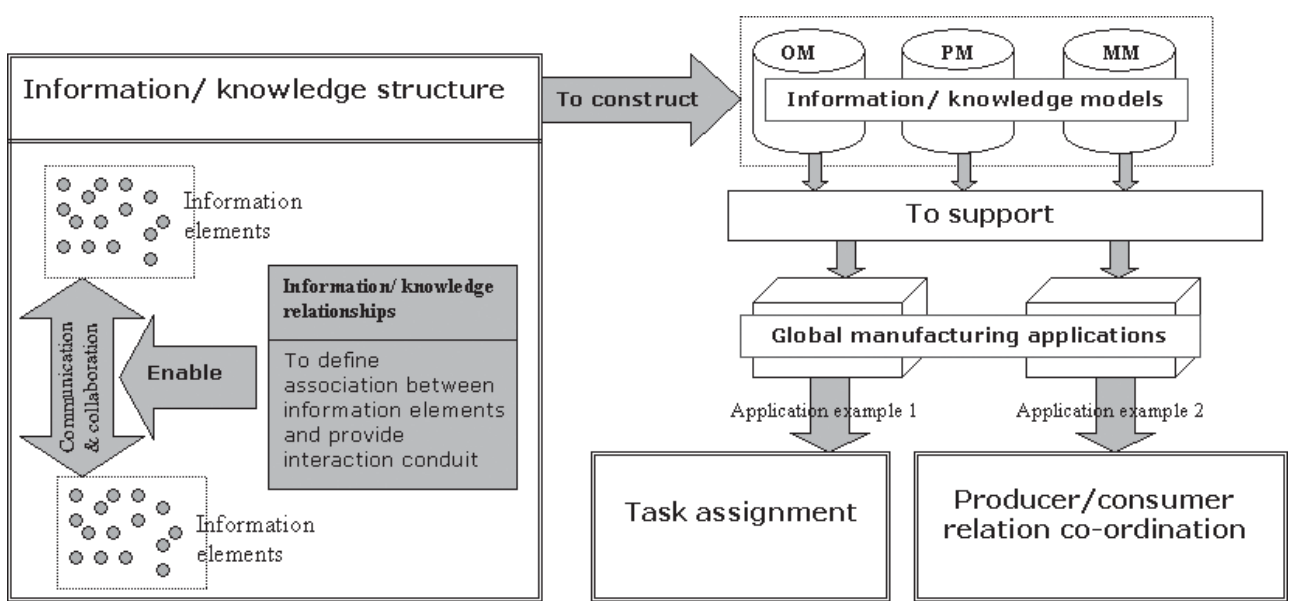

Fig. 13 Context of information and knowledge relationships in global manufacturing decision support

MM, the PM, and the OM discussed in the last sections, a case study has been pursued and is presented here. The objective is to investigate the application of a Global Manufacturing Coordination System (GMCS) [16] developed on the Rational Unified Process [34], object-oriented DBMS ObjectStore, and Visual $\mathrm{C}++$, to a real industrial environment.

\subsection{The context of information and knowledge relationships to support global manufacturing decisions}

The way in which the defined information and knowledge relationships are used to support global manufacturing decisions is illustrated in Fig. 13. Information and knowledge relationships define the links between information elements and enable communication between information elements. Both information element identification and information relationship definition form the foundation of information and knowledge structures. Information and knowledge models (OM, PM, and MM), working as information and knowledge repositories, are constructed according to the information and knowledge structures. The retrieval of the right information and knowledge from the information and knowledge models (OM, PM, and MM) supports the right decisions of global manufacturing applications such as task assignment (TA) and producer/ consumer relation coordination (PCRC). As the arrow shows in Fig. 13, information and knowledge relationships initiate the above process. Without the correct information and knowledge relationships, information elements cannot talk to each other. The collaboration between them is impossible. Hence, the global manufacturing coordination system (GMCS) cannot function as desired.

\subsection{A case study}

The information implemented within the GMCS described in this section is collected from Aeolus Automotive Corporation (AAC), one of the biggest automotive corporations in China which has close partnerships with French Citreon, American General Motor, Japanese Nissan, South Korean Qiya, and Taiwan Yulong. Its products cover different ranges of final products, components, and subassemblies for trucks, cars, and coaches with its production facilities dispersed all over China and other Asian countries, and with suppliers all over the world. Consequently, they have experience of global manufacturing decisions such as TA and coordination of PCRC. The GMCS was developed to support these decisions. Figure 14 is the overview of the GMCS application to AAC highlighting the role of the information and knowledge models.

This section discusses one example of the case study - one subfunction of the TA application, which is to organize manufacturing facilities to fulfil the production tasks. The following discussion about the case example of the GMCS system to AAC is based on two key assumptions. The first assumption is to take only one product type, i.e. coach EQ6890LK out of all the product ranges as an example; Assumption 2 is that the facilities involved only comprise the coach final assembly facility and its first tier suppliers, i.e. engine manufacturing facilities, transmission case manufacturing facilities, and other immediate subassembly/component manufacturing facilities.

How the information and knowledge relationships are used within the GMCS to guide the three models to work together to support the case example is illustrated in Fig. 15 with a collaboration diagram presented in UML. In the collaboration diagrams, objects are drawn as rectangles, and links between objects show the information interactions with 


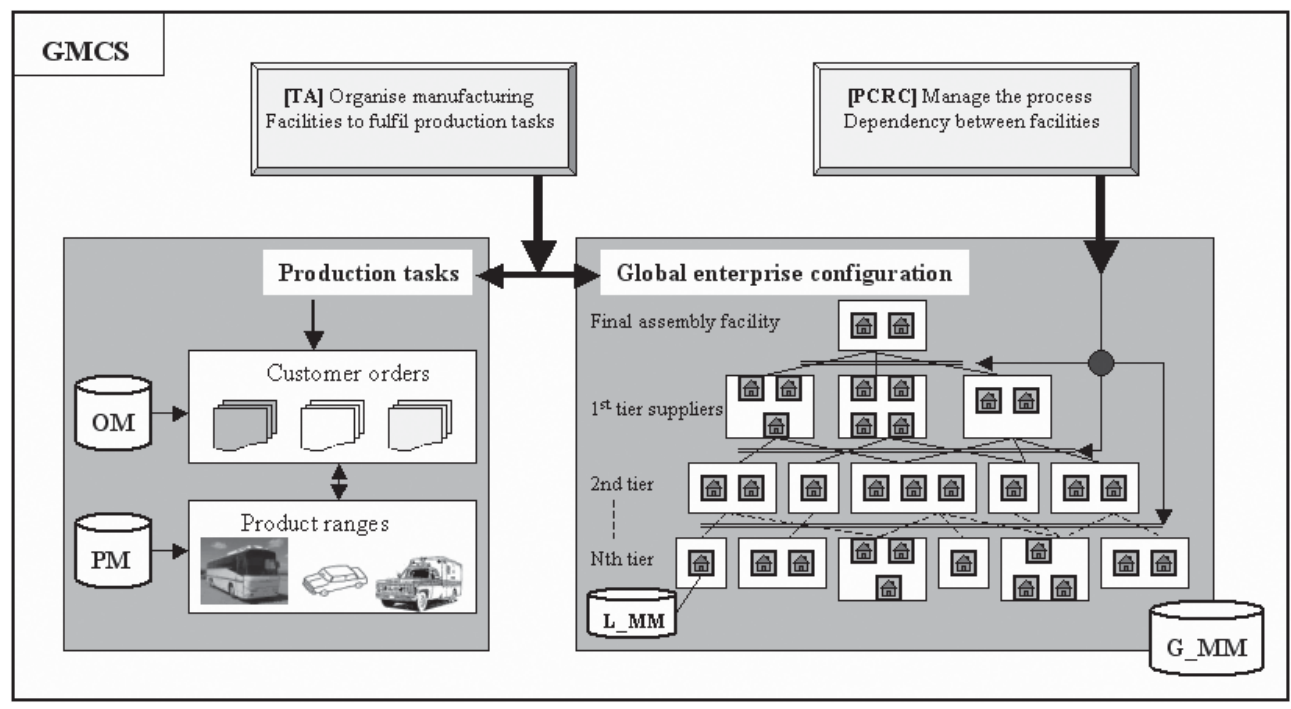

Fig. 14 Overview of the GMCS application to AAC

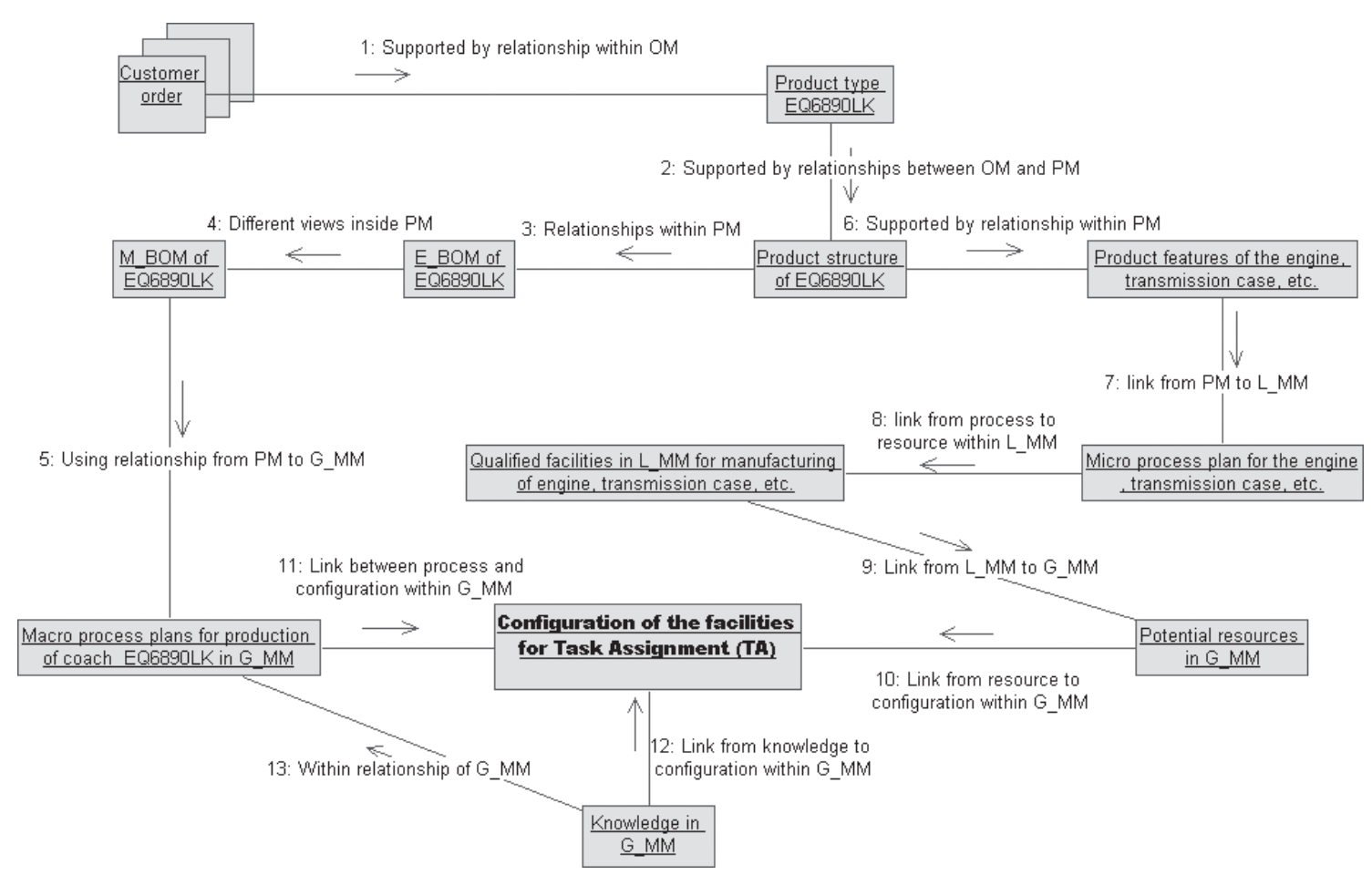

Fig. 15 Collaboration diagram to show interactions between models to support configuration of manufacturing facilities for Task Assignment application in global manufacturing

messages in text. The whole TA process starts from customer orders. According to the relationship between CustomerOrder and Product within the OM, GMCS can work out the product types in the order, for example EQ6890LK. Following the link from the OM to the PM as modelled in Fig. 10, the system will also find out the information about product structure. Within the PM, using the relationships between different views of the product, particularly DesignView and ManufacturingView (see Fig. 8), an Engineering BOM (E_BOM) and a Manufacturing BOM (M_BOM) can be generated. With the support from the link between ManufacturingView in the PM and global Process in the G_MM as modelled in Fig. 9, the requirements for a macroprocess plan are formed based on the M_BOM information. In the meantime, following the relationship between Product and its Characteristics within the PM (see Fig. 8), product features can be identified. Using the link between product features within the 


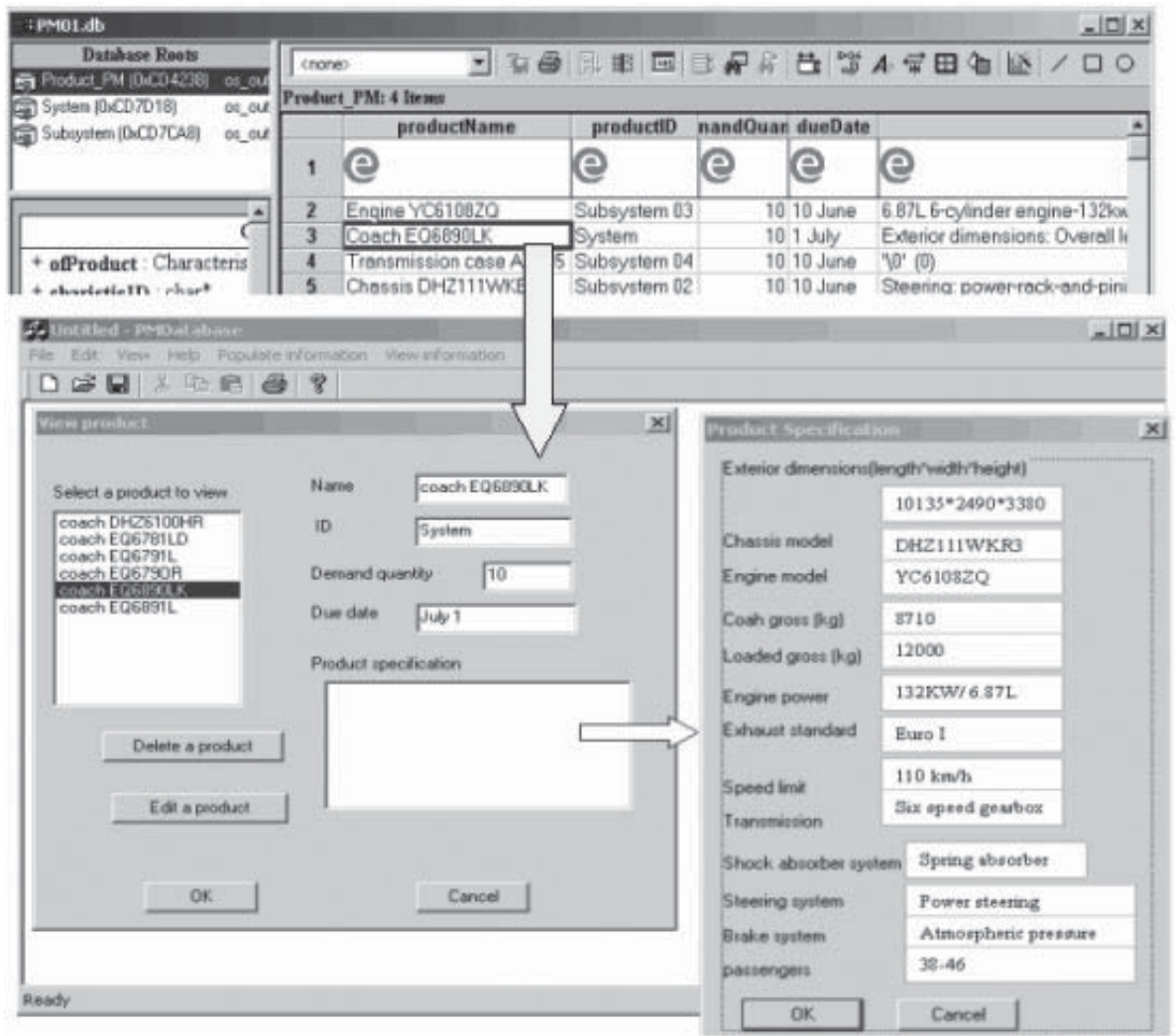

Fig. 16 (a) Product information about coach EQ6890LK captured in the PM

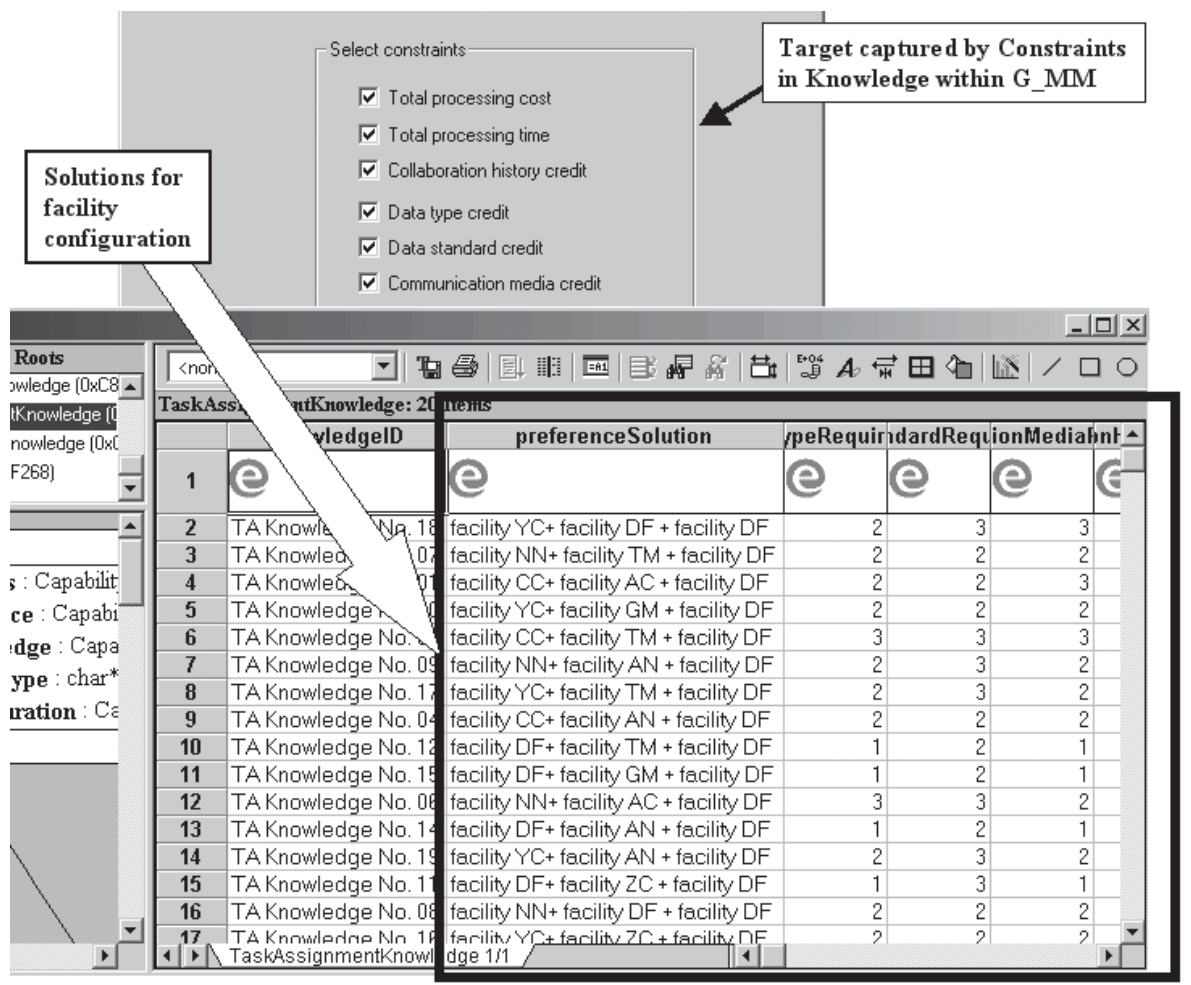

Fig. 16 (b) Configurations of manufacturing facilities for production of coach EQ6890LK 
$\mathrm{PM}$ and process evaluation within the L_MM in Fig. 11, qualified local facilities for the product with required features can be identified. Those qualified local facilities will be transferred to the G_MM as potential candidates (global Resource) based on the interaction between the L_MM and the G_MM (see Fig. 11). Inside the G_MM, the Knowledge about Configuration and its links to Resource and Process (macroprocess plan) enable the GMCS to form the configuration of manufacturing facilities that can match the requirements of a macroprocess plan based on the M_BOM. The GMCS then generates a list of configurations according to the target Constraints (modelled as an element of Knowledge in Fig. 6) such as lowest cost, shortest processing time, collaboration history credit, or overall performance.

Figure 16 provides a screenshot of the results generated by the GMCS using the information relationships to configure facilities for the production of the coach EQ6890LK, which is one of the product types in the product order. Detail product information is captured in the PM and shown in Fig. 16(a), while Fig. 16(b) shows the configuration results with consideration of target constraints.

Through the case study, it is clear that the right global manufacturing decisions such as TA in big companies such as AAC can only be made with efficient information and knowledge support. The relationships between different types of information and knowledge including customer order information, product information, manufacturing-related information and knowledge provide the mechanism to interact between the information and knowledge models. The success of the case study of using the information and knowledge relationships to support global facility configuration will motivate the authors' further research on exploration of the MM, $\mathrm{PM}$, and OM concept in more depth and width.

\section{DISCUSSION AND CONCLUSIONS}

This paper has discussed the modelling of information and knowledge relationships for global manufacturing decisions to tackle the complexity of the information and knowledge types involved in global manufacturing decision-making.

Three types of relationship have been explored and represented by UML class diagrams. Firstly, the information relationship within one single information and knowledge model, i.e. G_MM, has been explored by highlighting the definition of the Knowledge class in the manufacturing model and ManufacturingView class in the product model. The definition of the Knowledge class makes the manufacturing model (G_MM) intelligent and provides the conduit for different information elements in the manufacturing model to communicate. Secondly, information relationships between different information and knowledge models at the global level have been realized by sharing the common information structure between information classes. Thus, the manufacturing model (G_MM) can interact with the product model and order model so that the three models can collaborate to support global manufacturing decisions. Thirdly, the information relationship between the manufacturing models at global level and local level has been identified.

The work introduced in this paper has explored three types of relationship between information and knowledge in three particular models, which facilitates the information and knowledge model support for global manufacturing decisions. The general ideas and considerations for the information and knowledge relationships as well as their representation in the information and knowledge structures presented in this paper are of significant value to further work. The approach of categorizing information and knowledge into domain specific areas and also specifying clear relationships between them has the potential to be extended to more complex knowledge support systems. Our future research efforts will aim to advance a more detailed understanding of the relationships between information and knowledge models at different organizational levels, and also to explore new types of information and knowledge relationship to expand the application of the information and knowledge models to the full breadth of manufacturing decision-making.

\section{ACKNOWLEDGEMENT}

The authors are grateful to the Wolfson School of Mechanical and Manufacturing Engineering of Loughborough University for the financial support they provided towards the research work reported in this paper.

\section{REFERENCES}

1 Gibbons, W. M., Ranta, M., Scott, T. M., and Mantyla, M. Information management and process improvement using data mining technique. International Problems Solving: Methodologies and Approaches, Proceedings, Lecture Notes in Artificial Intelligence, 2000, 18(21), 93-98.

2 Maropoulos, P. G. Digital enterprise technology defining perspectives and research priorities. Int. J. Computer Integrated Mfg, 2003, 16(7-8), 467-478. 
3 Choy, K. L. and Lee, W. B. A generic supplier management tool for outsourcing manufacturing. Supply Chain Mgmt - An Int. J., 2003, 8(2), 140-154.

4 Rezayat, M. The enterprise-web portal for life cycle support. Computer-Aided Des., 2000, 32(2), 85-96.

5 Harding, J. A., Popplewell, K., Fung, R. Y. K., and Omar, A. R. An intelligent information framework relating customer requirements and product characteristics. Computers in Ind., 2001, 44(1), 51-65.

6 Tsai, C. Y., Sun, T. H., and Huang, J. X. A web-based XML information sharing system for collaborative product development. Int. J. Prod. Res., 2006, 44(15), 2955-2976.

7 Petersen, K. J., Handfield, R. B., and Ragatz, G. L. A model of supplier integration into new product development. J. Prod. Innovation Mgmt, 2003, 20(4), 284-299.

8 Young, R. I. M., Espinosa, A., Gunendran, G., Guerra, D., and Liu, S. Information and knowledge sharing in design decision support. In Proceedings of the 10th International Conference on Concurrent engineering, Madeira, Portugal, 2003, pp. 147-153.

9 Hicks, B. J., Cully, S. J., Allen, R. D., and Mullineux, G. A framework for the requirements of capturing, storing and reusing information and knowledge in engineering design. Int. J. Inf. Mgmt, 2002, 22, 263-280.

10 Pontrandolfo, P. and Okagbaa, O. G. Global manufacturing: a review and a framework for planning a global co-operation. Int. J. Prod. Res., 1999, 37(1), 1-19.

11 SCOR5, Supply-Chain Operations Reference-model (version 5.0). Supply-chain Council, Inc., www. supply-chain.org

12 Mallick, D. N. and Mukhopadhyay, S. K. Local design versus global design: a strategic business choice. Eur. J. Op. Res., 2001, 131, 389-399.

13 Dorador, J. M. and Young, R. I. M. Application of IDEF0, IDEF3, and UML methodologies in the creation of information models. Int. J. Computer Integrated Mfg, 2000, 13(5), 430-445.

14 Kim, C. H., Weston, R. H., Hodgson, A., and Lee, K. H. The complementary use of IDEF and UML modelling approaches. Computers in Ind., 2003, 50(1), 35-56.

15 Liu, S. and Young, R. I. M. Utilising information and knowledge models to support global manufacturing co-ordination decisions. Int. J. Computer Integrated Mfg, 2004, 17(6), 479-492.

16 Liu, S. Manufacturing information and knowledge models to support global manufacturing co-ordination. PhD Thesis, 2004, Loughborough University, UK.

17 Giachetti, R. E. A standard manufacturing information model to support design for manufacturing in virtual enterprises. J. Intell. Mfg, 1999, 10, 49-60.

18 Zhao, J., Cheung, W. M., and Young, R. I. M. A consistent manufacturing data model to support virtual enterprises. Int. J. Agile Mgmt Syst., 1999, 1 (3), 150-158.
19 Zhang, W. J. and $\mathbf{L i}, \mathbf{Q}$. Information modelling for made-to-order virtual enterprise manufacturing systems. Computer-Aided Des., 1999, 31, 611-619.

20 Molina, G. A. A manufacturing model to support data driven applications for design and manufacture. PhD Thesis, 1995, Loughborough University, UK.

21 Gunendran, A. G. and Young, R. I. M. An information and knowledge framework for multi-perspective design and manufacture. Int. J. Computer Integrated Mfg, 2006, 19(4), 326-338.

22 Harding, J. A knowledge representation model to support concurrent engineering team working. $\mathrm{PhD}$ Thesis, 1996, Loughborough University, UK.

23 Mills, J. J. and Goossenaerts, J. Towards information and knowledge in product realisation infrastructures. In Global engineering, manufacturing and enterprise networks, Melbourne, Australia, 2001, pp. 245-254 (Kluwer Academic Publishers, Massachusetts, USA).

24 Deneux, D. and Wang, X. H. A knowledge model for functional re-design. Engng Applics of Artif. Intell., 2000, 13, 85-98.

25 Klein, M. R. and Methlie, L. B. Knowledge-based decision support systems with applications in business, 1995 (John Wiley \& Sons, New York).

26 Costa, C. A. and Young, R. I. M. Product range models supporting design knowledge reuse. Proc. Instn Mech. Engrs Part B: J. Engineering Manufacture, 2001, 215(3), 323-337.

27 Peng, T. K. and Trappey, J. C. A step toward STEPcompatible engineering data management: the data models of product structure and engineering changes. Robotics and Computer-Integrated Mfg, 1998, 14, 89-109.

28 Streppel, T., Lutters, E., Brinke, E. T., and Kals, H. Process planning for sheet metal parts based on information management. Int. J. Prod. Res., 2000, 38(18), 4701-4716.

29 McMahon, C. A. and Browne, J. CADCAM: principles, practice and manufacturing management, 2nd edition, 1998 (Addison-Wesley, London).

30 Ullman, D. G. The mechanical design process, 2nd edition, 1997 (McGraw-Hill Companies Inc., San Fransisco).

31 Chang, S. H., Lee, W. L., and Li, R. K. Manufacturing bill-of-material planning. Prod. Plann. Control, 1997, 8(5), 437-450.

32 Wu, N. Q., Mao, N., and Qian, Y. M. An approach to partner selection in agile manufacturing. J. Intell. Mfg, 1999, 10, 519-529.

33 Minis, I., Hemmman, J. W., Lam, G., and Lin, E. A generative approach for concurrent manufacturability evaluation and subcontractors selection. J. Mfg Syst., 1999, 18(6), 383-395.

34 Quatrani, T. Visual modelling with rational rose and UML, 2000 (Addison Wesley Longman, Inc., Boston, USA). 